J Steroid Biochem Mol Biol. 2010 July ; 121(1-2): 425-429. doi:10.1016/j.jsbmb.2010.03.042.

\title{
Vitamin D and Diabetes
}

\author{
ANASTASSIOS G. PITTAS, MD ${ }^{1},{ }^{*}$ and BESS DAWSON-HUGHES, MD ${ }^{1,2}$ \\ ${ }^{1}$ Division of Endocrinology, Diabetes and Metabolism, Tufts Medical Center, Boston, MA \\ 2 Bone Metabolism Laboratory, Jean Mayer US Department of Agriculture Human Nutrition \\ Research Center on Aging, Tufts University, Boston, MA
}

\begin{abstract}
On the basis of evidence from animal and human studies, vitamin $\mathrm{D}$ has emerged as a potential risk modifier for type 1 and type 2 diabetes (type 1 diabetes and type 2 diabetes). Vitamin $\mathrm{D}$ is thought to have both direct (through activation of the vitamin D receptor) and indirect (via regulation of calcium homeostasis) effects on various mechanisms related to the pathophysiology of both types of diabetes, including pancreatic beta cell dysfunction, impaired insulin action and systemic inflammation. Observational case-control studies have shown that vitamin D supplementation in pregnancy or early childhood is associated with reduced risk of incident type 1 diabetes. There are no trials on the effect of vitamin D (ergocalciferol or cholecalciferol) on type 1 diabetes. An association between vitamin D insufficiency and incident type 2 diabetes has been reported in longitudinal observational studies, but the association is not consistent. Results from small underpowered trials and post-hoc analyses of data from larger trials designed for bonespecific outcomes show no effect of vitamin D supplementation on glycemia in healthy adults but vitamin D may retard the progression to diabetes in adults with glucose intolerance. Because vitamin $\mathrm{D}$ is an excellent marker of general health status, the positive results reported in some observational studies might reflect unmeasured and unaccounted confounding. Therefore, the hypothesis that vitamin D may modify diabetes risk needs to be confirmed in trials specifically designed for that purpose.
\end{abstract}

\section{Keywords}

Vitamin D; diabetes mellitus

\section{Introduction}

Diabetes, a chronic condition associated with serious morbidity, increased mortality and accelerated health care costs, is rapidly becoming a global epidemic. The total number of people with diabetes world-wide is expected to rise from 171 million in 2000 to 366 million by 2030 [1]. Although the majority of new cases are due to type 2 diabetes, the incidence of type 1 diabetes has been increasing as well. The growing incidence and prevalence of diabetes highlights the need for innovative approaches for the management and prevention

\footnotetext{
(C) 2010 Elsevier Ltd. All rights reserved.

* Corresponding Author: Anastassios G. Pittas, M.D. MS., Division of Endocrinology, Diabetes and Metabolism, Tufts Medical Center, Box 268, 800 Washington Street, \#268, Boston, MA 02111; apittas@ tuftsmedicalcenter.org.

Publisher's Disclaimer: This is a PDF file of an unedited manuscript that has been accepted for publication. As a service to our customers we are providing this early version of the manuscript. The manuscript will undergo copyediting, typesetting, and review of the resulting proof before it is published in its final citable form. Please note that during the production process errors may be discovered which could affect the content, and all legal disclaimers that apply to the journal pertain.
} 
of the disease. Epidemiologic data suggest that 9 out of 10 cases of type 2 diabetes could be attributed to modifiable habits and lifestyle [2]; however lifestyle changes are difficult to achieve and maintain long term. Much less is known about modifiable risk factors for type 1 diabetes. Therefore, identification of modifiable risk factors for prevention of both types of diabetes is needed. Recently, there has been increasing evidence from animal and human studies, to suggest that vitamin D may play a role in modifying risk of diabetes [3].

\section{Potential mechanisms of action of vitamin D on glucose metabolism}

Type 1 diabetes is due to autoimmune destruction of pancreatic beta cells leading to absolute insulin deficiency. For type 2 diabetes to develop, impaired pancreatic beta-cell function, insulin resistance and systemic inflammation are often present. There are several lines of evidence to support that vitamin D influences all these pathways [3].

A role for vitamin $\mathrm{D}$ in pancreatic beta-cell function might be mediated by the binding of circulating 1,25-dihydroxyvitamin $\mathrm{D}$ to the beta-cell vitamin $\mathrm{D}$ receptor. Alternatively, vitamin D could function through activation of 25 -hydroxyvitamin D (25OHD) by 1-alphahydroxylase, which is expressed in beta cells. Vitamin D may directly enhance insulin sensitivity by stimulating the expression of insulin receptors and/or by activating peroxisome proliferator-activated receptor (PPAR- $\delta$ ), a factor implicated in the regulation of fatty acid metabolism in skeletal muscle and adipose tissue. Vitamin D may also affect insulin secretion and sensitivity indirectly via its role in regulating extracellular calcium concentration and flux through cell membranes in the beta cell and peripheral insulin-target tissues. Finally, the well-recognized immunomodulatory properties of vitamin D in relation to T-cell activity [4] would influence a number of steps in the autoimmune process leading to type 1 diabetes.

\section{Evidence from human studies linking vitamin $D$ and type 1 diabetes}

\subsection{Observational studies for type 1 diabetes}

Vitamin D insufficiency has long been suspected to be a risk factor for type 1 diabetes. Indirect evidence comes from studies that have reported higher incidence and prevalence of type 1 diabetes in countries at higher latitude compared to counties at lower latitude [5]. There is also seasonal variation in the birth date of patients who subsequently develop 1 diabetes, with risk increasing with births in the spring-summer months, which suggest an effect of lower sunshine in utero [6]. Type 1 diabetes is also more commonly diagnosed in the winter $[7,8]$. These ecological studies use latitude and season as proxies for limited sunshine, which is associated with lower vitamin D status; however, this is only a hypothesis as other factors may be responsible for the association (e.g. virus infections or sedentary behaviors, which are more common in the winter).

There are four case-control studies (retrospective) and one longitudinal (prospective, Table 1) cohort study (all from Europe) reporting an association between vitamin $D$ status in the pregnant mother or the infant and incident type 1 diabetes [9]. These studies have reported an inverse association between intake of vitamin D supplements during lactation [10] or infancy [11], or intake of cod liver oil (a major source of vitamin D in certain countries) during pregnancy or infancy [12] and incident type 1 diabetes. A recent meta-analysis of these studies reported a lower risk for developing type 1 diabetes with self-reported vitamin D supplementation in early childhood (odds ratio $0.71,95 \%$ confidence interval [CI] 0.60 to 0.84) [9]. Other studies have found that increased vitamin D intake during pregnancy [13] or during infancy [14] is associated with reduced diabetes-related autoimmunity, providing indirect evidence for a beneficial role of vitamin $\mathrm{D}$ on the pathophysiology of type 1 
diabetes. However, the association between vitamin D intake during pregnancy or in early life and type 1 diabetes risk is not consistent $[12,14]$.

\subsection{Randomized controlled trials in relation to type 1 diabetes}

There are no trials that have reported the effect of vitamin $\mathrm{D}_{2}$ (ergocalciferol) or $\mathrm{D}_{3}$ (cholecalciferol) supplementation on prevention or treatment of type 1 diabetes. In a pilot, open-label trial in 70 children, mean age of 14 years, with recent-onset type 1 diabetes, calcitriol had a modest favorable effect on residual pancreatic beta-cell function; however, the reduction in hemoglobin A1c concentration after 1 year was not statistically significant [15].

\section{Evidence from human studies linking vitamin $D$ and type 2 diabetes}

\subsection{Observational studies for type 2 diabetes}

Several cross sectional studies have examined the association between vitamin D status and prevalence of glucose intolerance or type 2 diabetes. Although most have reported an inverse association between vitamin D status and glucose intolerance, others failed to show such an association (studies reviewed by Pittas et al [3]).

Two longitudinal cohort studies from the US and one study from Finland (which analyzed 2 separate cohorts) have reported an association between vitamin $\mathrm{D}$ status and risk of incident type 2 diabetes [16-18] (Table 1). In the Women's Health Study, an intake of 511 IU/day or more of vitamin $\mathrm{D}$ was associated with lower risk of incident type 2 diabetes compared with an intake of $159 \mathrm{IU} /$ day or less ( 2.7 vs. $5.6 \%$ of the cohort developed type 2 diabetes, respectively) [16]. However, this analysis did not adjust for any covariates other than age. In a subgroup analysis from the Nurses Health Study, there was a statistically significant association with lower risk of type 2 diabetes among women who reported the highest intake of both vitamin D and calcium (RR 0.67; 95\% CI 0.49, 0.90 for intake of $800 \mathrm{IU} /$ day vitamin D and $1200 \mathrm{mg} /$ day calcium vs. $400 \mathrm{IU} /$ day vitamin D and $600 \mathrm{mg} /$ day calcium) [17]. A statistically significant association between higher vitamin D status and lower risk of incident type 2 diabetes was also reported among men in the Mini-Finland Health Survey cohort (RR 0.17; 95\% CI 0.05, 0.52; comparing 25[OH]D concentration of $75 \mathrm{vs.} 22 \mathrm{nmol} /$ L) [18]. Three analyses (two in women [17,18] and one in men [18]) suggested a lower, but statistically non-significant, risk of type 2 diabetes among participants in the highest versus the lowest vitamin D status category, while one analysis in men reported a non-statistically significant increase in risk with higher vitamin D status.

\subsection{Randomized controlled trials in relation to type 2 diabetes}

There are seven controlled trials that have examined the effect of supplementation with a variety of formulations of vitamin $\mathrm{D}$ on type 2 diabetes related parameters (fasting plasma glucose, hemoglobin A1c or incident type 2 diabetes) (Table 2) [19-25]. Study duration varied from 2 months to 7 years and doses ranged from 400 IU/day to a single dose of 100,000 IU of vitamin D. In five studies that provided vitamin D supplementation without concomitant calcium, there was no effect on glycemic measures [19,20,23-25]. There are two trials that have reported the effect of combined vitamin $\mathrm{D}_{3}$ and calcium supplementation on type 2 diabetes, in post-hoc analyses. In one of these trials designed to assess bone related outcomes, combined vitamin $\mathrm{D}_{3}$ (700 IU/day) and calcium $(500 \mathrm{mg} / \mathrm{day})$ supplementation attenuated the increase in fasting glycemia in the subgroup of participants with impaired fasting glucose at baseline, but had no effect on fasting glycemia among those with normal glucose tolerance at baseline [21]. In contrast, combined vitamin $\mathrm{D}_{3}$ (400 IU/ day) and calcium supplementation (1,000 mg/day) in the Women's Health Initiative (WHI) trial did not reduce the risk of incident diabetes over a 7-year period [22]. In the WHI, there 
was also no significant effect of treatment on fasting glycemia or simple indices of insulin resistance. This null result in the WHI study may be due to the small dose of vitamin D (400 IU/day) given to the active treatment group and "cross contamination" as the trial design allowed all participants to take vitamin D supplements on their own during the trial.

\section{Summary of evidence from the human studies on type 1 and 2 Diabetes}

Although cross-sectional studies have reported relatively consistent associations between low vitamin D status and prevalent type 1 or type 2 diabetes [3,26], the evidence from longitudinal observational studies is sparse and inconclusive and, therefore, definite conclusions cannot be drawn for a variety of reasons: recall bias in the case-control studies in type 1 diabetes when the predictor (vitamin D status) was ascertained by recall years after the diagnosis of diabetes, considerable variability among the various cohorts, lack of adjustment for important confounders and, importantly, residual confounding given that vitamin $\mathrm{D}$ status is an excellent marker of overall health. It is also difficult to draw definitive conclusions from trials, because there is only a small underpowered trial in relation to type 1 diabetes that used the active form of vitamin $\mathrm{D}$ while trials in relation to type 2 diabetes were post-hoc analyses.

\section{Optimal intake of vitamin $D$ in relation to diabetes}

The optimal vitamin D intake and 25OHD concentration is currently hotly debated and there is growing consensus that vitamin D intakes above the current recommendations may be associated with better health outcomes. In the US, currently recommended intakes for vitamin D are $400 \mathrm{IU} /$ day for those aged 51-70 years and $600 \mathrm{IU} /$ day for those aged $>70$ years [27] but these intakes are currently under review by the US Institute of Medicine. Based on the available studies reviewed here, it is difficult to draw definitive conclusion for the optimal 25OHD level in relation to diabetes.

\section{Conclusions and future directions}

An inverse association between vitamin D status and both types of diabetes is suggested by observational studies. However, the lack of large prospective observational studies that have measured $25(\mathrm{OH}) \mathrm{D}$ as the exposure variable prior to ascertainment of the outcome and the lack of randomized trials specifically designed to test the effects of vitamin D on diabetes limits drawing any definitive conclusions. To better define the clinical role of vitamin D as a potential intervention for prevention and management of diabetes, high quality observational studies that measure $25(\mathrm{OH}) \mathrm{D}$ as the exposure variable and randomized controlled trials specifically designed to test such an hypothesis are needed.

\section{Acknowledgments}

Funded by NIH Research grants R01DK76092 and R01DK79003 (to AGP, funded by the National Institute of Diabetes and Digestive and Kidney Disease, and the NIH Office of Dietary Supplements), R21DK78867 (to AGP, funded by the National Institute of Diabetes and Digestive and Kidney Disease) and US Department of Agriculture Agreement 58-1950-9001 (to BDH).

\section{REFERENCES}

1. Wild S, Roglic G, Green A, Sicree R, King H. Global prevalence of diabetes: estimates for the year 2000 and projections for 2030. Diabetes Care 2004;27(5):1047-1053. [PubMed: 15111519]

2. Hu FB, Manson JE, Stampfer MJ, Colditz G, Liu S, Solomon CG, Willett WC. Diet, lifestyle, and the risk of type 2 diabetes mellitus in women. N Engl J Med 2001;345(11):790-797. [PubMed: 11556298] 
3. Pittas AG, Lau J, Hu FB, Dawson-Hughes B. The role of vitamin D and calcium in type 2 diabetes. A systematic review and meta-analysis. J Clin Endocrinol Metab 2007;92(6):2017-2029. [PubMed: 17389701]

4. van Etten E, Mathieu C. Immunoregulation by 1,25-dihydroxyvitamin D3: basic concepts. J Steroid Biochem Mol Biol 2005;97(1-2):93-101. [PubMed: 16046118]

5. Mohr SB, Garland CF, Gorham ED, Garland FC. The association between ultraviolet B irradiance, vitamin D status and incidence rates of type 1 diabetes in 51 regions worldwide. Diabetologia 2008;51(8):1391-1398. [PubMed: 18548227]

6. Vaiserman AM, Carstensen B, Voitenko VP, Tronko MD, Kravchenko VI, Khalangot MD, Mechova LV. Seasonality of birth in children and young adults (0-29 years) with type 1 diabetes in Ukraine. Diabetologia 2007;50(1):32-35. [PubMed: 17093948]

7. Christau B, Kromann H, Andersen OO, Christy M, Buschard K, Arnung K, Kristensen IH, Peitersen B, Steinrud J, Nerup J. Incidence, seasonal and geographical patterns of juvenile-onset insulindependent diabetes mellitus in Denmark. Diabetologia 1977;13(4):281-284. [PubMed: 913920]

8. Fishbein HA, LaPorte RE, Orchard TJ, Drash AL, Kuller LH, Wagener DK. The Pittsburgh insulindependent diabetes mellitus registry: seasonal incidence. Diabetologia 1982;23(2):83-85. [PubMed: 6751900]

9. Zipitis CS, Akobeng AK. Vitamin D supplementation in early childhood and risk of type 1 diabetes: a systematic review and meta-analysis. Archives of disease in childhood 2008;93(6):512-517. [PubMed: 18339654]

10. Tenconi MT, Devoti G, Comelli M, Pinon M, Capocchiano A, Calcaterra V, Pretti G. Major childhood infectious diseases and other determinants associated with type 1 diabetes: a casecontrol study. Acta diabetologica 2007;44(1):14-19. [PubMed: 17357880]

11. Hypponen E, Laara E, Reunanen A, Jarvelin MR, Virtanen SM. Intake of vitamin D and risk of type 1 diabetes: a birth-cohort study. Lancet 2001;358(9292):1500-1503. [PubMed: 11705562]

12. Stene LC, Joner G. Use of cod liver oil during the first year of life is associated with lower risk of childhood-onset type 1 diabetes: a large, population-based, case-control study. Am J Clin Nutr 2003;78(6):1128-1134. [PubMed: 14668274]

13. Brekke HK, Ludvigsson J. Vitamin D supplementation and diabetes-related autoimmunity in the ABIS study. Pediatric diabetes 2007;8(1):11-14. [PubMed: 17341286]

14. Fronczak CM, Baron AE, Chase HP, Ross C, Brady HL, Hoffman M, Eisenbarth GS, Rewers M, Norris JM. In utero dietary exposures and risk of islet autoimmunity in children. Diabetes Care 2003;26(12):3237-3242. [PubMed: 14633808]

15. Pitocco D, Crino A, Di Stasio E, Manfrini S, Guglielmi C, Spera S, Anguissola GB, Visalli N, Suraci C, Matteoli MC, Patera IP, Cavallo MG, Bizzarri C, Pozzilli P. The effects of calcitriol and nicotinamide on residual pancreatic beta-cell function in patients with recent-onset Type 1 diabetes (IMDIAB XI). Diabet Med 2006;23(8):920-923. [PubMed: 16911633]

16. Liu S, Song Y, Ford ES, Manson JE, Buring JE, Ridker PM. Dietary calcium, vitamin D, and the prevalence of metabolic syndrome in middle-aged and older U.S. women. Diabetes Care 2005;28(12):2926-2932. [PubMed: 16306556]

17. Pittas AG, Dawson-Hughes B, Li T, Van Dam RM, Willett WC, Manson JE, Hu FB. Vitamin D and calcium intake in relation to type 2 diabetes in women. Diabetes Care 2006;29(3):650-656. [PubMed: 16505521]

18. Knekt P, Laaksonen M, Mattila C, Harkanen T, Marniemi J, Heliovaara M, Rissanen H, Montonen J, Reunanen A. Serum vitamin D and subsequent occurrence of type 2 diabetes. Epidemiology (Cambridge, Mass 2008;19(5):666-671.

19. Nilas L, Christiansen C. Treatment with vitamin D or its analogues does not change body weight or blood glucose level in postmenopausal women. Int J Obes 1984;8(5):407-411. [PubMed: 6549176]

20. Sugden JA, Davies JI, Witham MD, Morris AD, Struthers AD. Vitamin D improves endothelial function in patients with Type 2 diabetes mellitus and low vitamin D levels. Diabet Med 2008;25(3):320-325. [PubMed: 18279409] 
21. Pittas AG, Harris SS, Stark PC, Dawson-Hughes B. The effects of calcium and vitamin D supplementation on blood glucose and markers of inflammation in nondiabetic adults. Diabetes Care 2007;30(4):980-986. [PubMed: 17277040]

22. de Boer IH, Tinker LF, Connelly S, Curb JD, Howard BV, Kestenbaum B, Larson JC, Manson JE, Margolis KL, Siscovick DS, Weiss NS. Calcium plus vitamin D supplementation and the risk of incident diabetes in the Women's Health Initiative. Diabetes Care 2008;31(4):701-707. [PubMed: 18235052]

23. Jorde R, Figenschau Y. Supplementation with cholecalciferol does not improve glycaemic control in diabetic subjects with normal serum 25-hydroxyvitamin D levels. Eur J Nutr 2009;48(6):349_ 354. [PubMed: 19370371]

24. Zittermann A, Frisch S, Berthold HK, Gotting C, Kuhn J, Kleesiek K, Stehle P, Koertke H, Koerfer R. Vitamin D supplementation enhances the beneficial effects of weight loss on cardiovascular disease risk markers. Am J Clin Nutr 2009;89(5):1321-1327. [PubMed: 19321573]

25. von Hurst PR, Stonehouse W, Coad J. Vitamin D supplementation reduces insulin resistance in South Asian women living in New Zealand who are insulin resistant and vitamin D deficient - a randomised, placebo-controlled trial. Br J Nutr 2009:1-7. [PubMed: 19995474]

26. Nemerovski CW, Dorsch MP, Simpson RU, Bone HG, Aaronson KD, Bleske BE. Vitamin D and cardiovascular disease. Pharmacotherapy 2009;29(6):691-708. [PubMed: 19476421]

27. I.o.M. Food and Nutrient Board. Dietary reference intakes for calcium, phosphorus, magnesium, vitamin D and fluoride. National Academy Press; Washington, DC: 2003. 


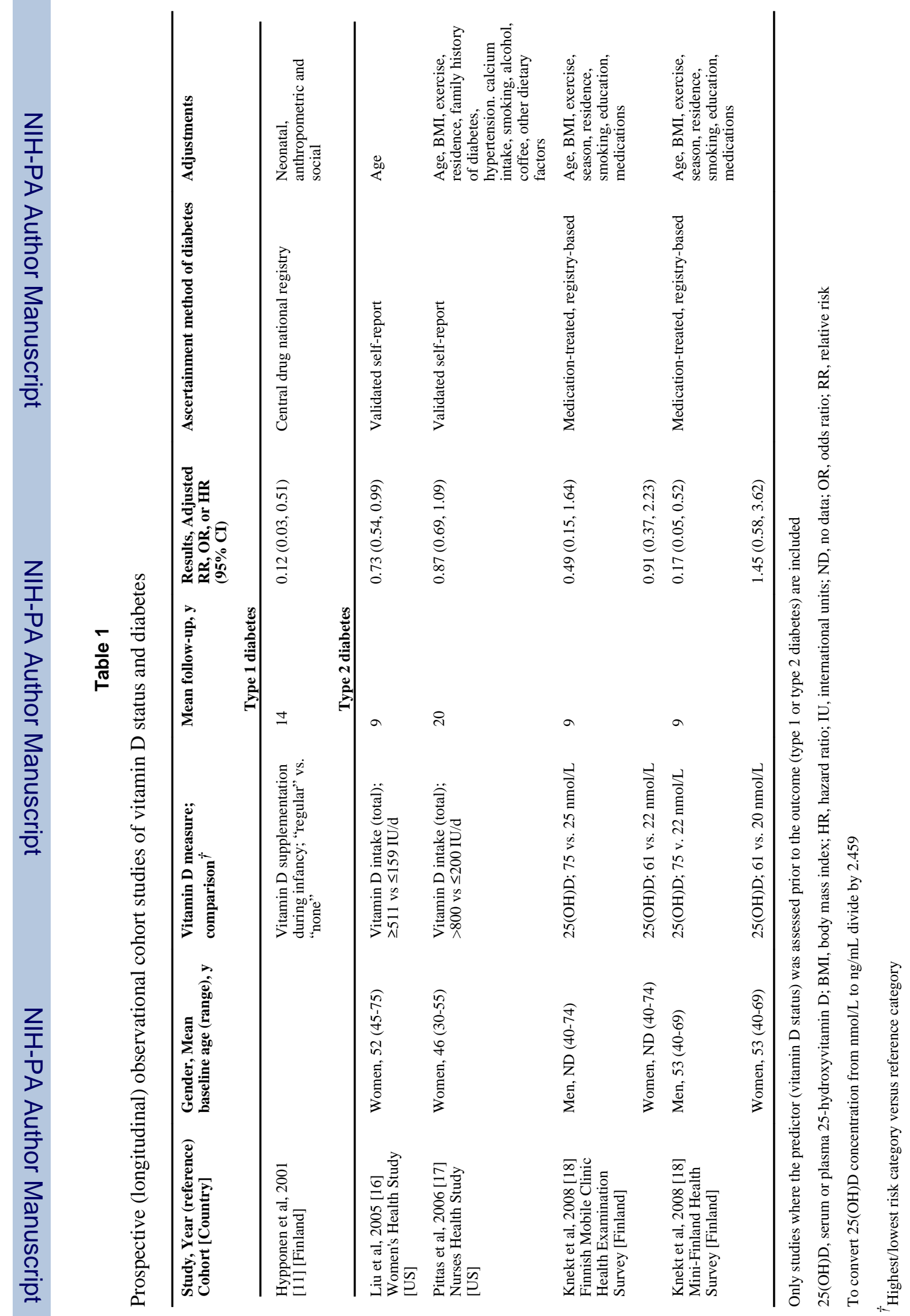




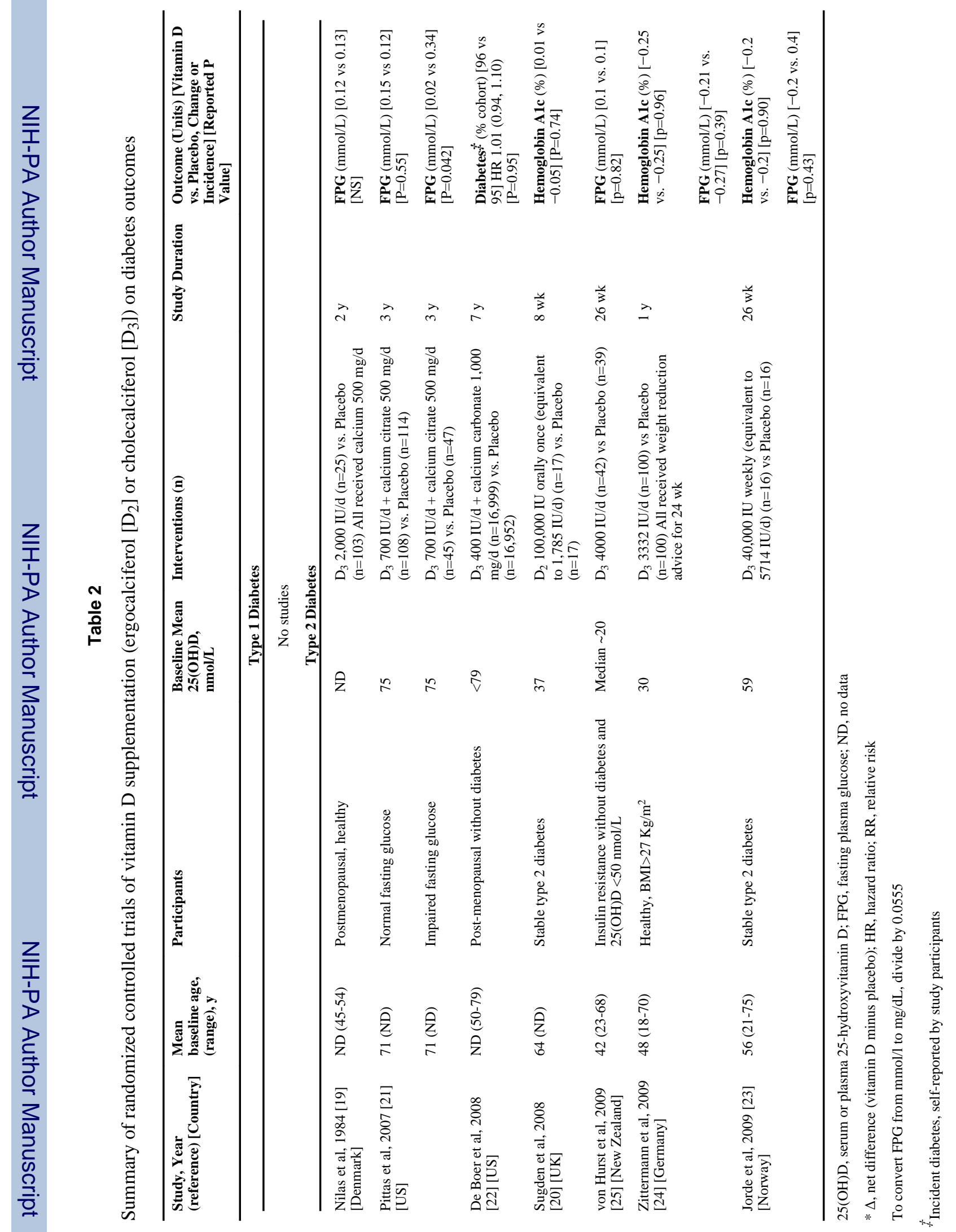

